\title{
E-LEARNING FOR AGRICULTURE EDUCATION IN INDIA
}

\author{
Himanshu Agarwal ${ }^{1}$, Arvind Kumar ${ }^{2}$ \\ ${ }^{1}$ Dept. of Software Engineering, ${ }^{2}$ Dept. of Discovery Park, \\ ${ }^{12}$ Indian Institute of Information Technology \\ Allahabad-211012, India \\ 1agarwal1488@gmail.com, 2arvind1266@gmail.com
}

\begin{abstract}
E-learning is a modern way of learning now days. It includes electronic media in the field of education. E-learning makes use of (ICT) information and communication technology. Now a day, In every field like learning in medical or learning in agriculture, e-learning is going popular to use. E-learning involves various types of media that provide video, audio, images and text. E-learning uses the intranet/ extranet / internet, and widens the horizon of traditional learning. This article explores the time when the concept of elearning was introduced, mentions its basic principles, discuss the ways in which it is superior than the traditional educational system. E-Agriculture is a rising field that specialize in the improvement of agricultural and rural development through improved and updated information and communication processes. Specifically, e-Agriculture involves the conceptualization, design, development, analysis and application of innovative ways in which to use information and communication technologies (IT) within the rural domain, with a primary specialize in agriculture. E-Agriculture may be a comparatively new term and that we totally expect its scope to alter and evolve as our understanding of the realm grows.
\end{abstract}

Keywords: E-Education in agriculture, E-learning, E-Education system, Internet-Education, Impact of E-Learning in Education.

\section{INTRODUCTION}

E-leaning focuses on usage of technology in the field of education and learning. E learning refers to the use of advanced technology of information communication in the learning process where the advanced technology comprises of electronic media. In the current scenario, the rapid growth of information and communication technology has led to the alphabet "e" becoming the symbol of this latest age of information technology. The alphabet "e" is used as abbreviation for electronics. Thus, words prefixed with " $\mathrm{e}$ " are currently emerging in every second field, like e- learning, ehealth, e-business, e-government and many more. In the current scenario, where the world is being dominated by globalization, networking and information technology has reached its peak, e-learning plays a vital role in the field of education.

In the field of agriculture, according to Nelson, "Today, farmers feed 6 billion people. However, some 800 million people go to bed hungry every night and 166 million children are malnourished. At the same time, current agricultural practices are responsible for dead zones at the mouths of the world's rivers and rapid species extinctions. By 2050, the human population will grow by two to three billion. The challenge for agriculture is not only producing more food but producing it in a sustainable manner while raising living standards for the poor, many of whom live and work in rural areas. All this must be done while dealing with the uncertain consequences of global warming and geopolitics. The solutions will include new policies, new technologies, and new production practices" (Nelson 2006)

\section{HISTORY OF E-LEARNING}

A revolution in the information technology and the emergence of web has made the human society take a huge leap. The focus of society is shifted from industry to information. The appearance of information technology has been the most important event at the start of this century. Information technology suddenly became an important element of every aspect of our society. Education is no exception. The use of multimedia and networking is welcomed by the field of education.

In 1960, the University of Illinois developed a classroom with linked computer terminals where the students could listen to recorded lectures of a particular course. This was the first time that some form of e-learning was followed. In the beginning of 1960s, some professors of Stanford University used computers to teach mathematics and reading in elementary schools. Computer based learning gave birth to many e-learning courses. With the growth of internet in 1990s, correspondence schools like University of Phoenix, started showing interest in 
virtual education. By 1994, the first online high school CALCampus came into existence. The combination of online education and face-to-face teaching methods has gained more success than using the two methods individually.

Some experts refer to the education in 21 st century as a multimedia network education. Educational informization is being accepted and promoted by all the nations around the world. A fact stated by the National Centre for Education Statistics that in 2008, there were 18 million students, who were enrolled in some online program worldwide, which was a $1.6 \%$ increase from 2002.In India, even though the statistics are not so high, still there is a large scope of online education [1].Under this situation, the education system and the teaching methods and many other things related to the education field are changing. And this transformation has given birth to elearning.

\section{THE BASIC PRINCIPLES}

The concept of e-learning grows in e-commerce, but it does not have a combined definition currently. Originally, elearning focuses on study based on the network or internet. But practically, the multimedia learning is included under elearning. At the abstract level, e-learning refers to use of electronic media in the field of study, and in a more specific way, it deals with education carried out using internet. Since e-learning is user friendly and easy to interact, hence its use is now preferred at a global level.

The basic principle of e-learning is the Construction Principle Theory, which came into existence after the emergence of network and multimedia. In the present scenario, knowledge changes rapidly, hence scientific knowledge is not sufficient enough to suit the requirements of the changing times. The emergence of e-learning gave rise to the construction principle, whose study views are:

\subsection{Study is a Significant Construction Process:}

The level of awareness decides the extent to which people understand things. People don't gain the knowledge through the instructions given to them by the teacher, but by their own experience with the unit they are studying. The correlation between the person who is learning and the external environment leads to the development of knowledge

\subsection{Learner: An Active Factor:}

In the process of imparting knowledge, one of the active factors is learner. The cognitive structure of the learner affects the learning process and its results.

Each learner has its own experience and practical knowledge. Thus sometimes, the information obtained is not identical with the real situation. In such cases, consulting can be the only solution. Due to the variance of learners worldwide, the focus of teaching appraisal should be on cognition process of the students instead of the result of learning.

\subsection{Study is a Real Experience:}

The real world situation makes the study more effective. The main aim of imparting knowledge is to make the learner understand the things, as well as to make him/her utilize the knowledge in real world situations.

This explains that the construction principle is centred on the student. The teacher acts like the organizer or the promoter of the entire process of teaching.

\section{THE BENEFITS OF E-LEARNING}

E-learning is yet to become the large scale method of training teachers in the educational field. When compared with the traditional methods of training teachers, e-learning has the merits shown below:

\subsection{Low Cost:}

E-learning is far cheaper than traditional methods of teaching because of no use of paper and pencil and with the reduced expense of teacher training. It can be carried out at any place and at any time.

It also saves a lot of time and now the various parameters will not be limited to the size of the class and number of students.

\subsection{Flexible:}

E-learning can be carried out anywhere without strict time boundations it leads to a more flexible environment for students.

\subsection{Personalization}

Unlike traditional teaching practices in e-learning the training material is not chosen by teacher or some organization and can help students to obtain their own requirement of knowledge.

\section{APPLICATION IN EDUCATION TRAINING}

E-learning is superior to traditional learning when it comes to reduction of training time, cost and having better effect. Elearning has promoted student learning and improved the process of education training. It has appeared in following aspects:

\subsection{Application of Various Learning Patterns:}

With the development of computer technology, various learning patterns have emerged. A good e-learning pattern includes both formal and informal learning. The aim of blended learning or formal learning is to confirm that some 
study patterns are superior to others. A way is designed, which combines the strategies of learning, the methods, the modes of transmission and the medium, and gives birth to online and offline, named as $\mathrm{E}+\mathrm{C}$ combination plan. It stands for elearning+ classroom. The main goal of blended learning is to achieve study goals. But in e-learning education, informal training is more popular, as the learning is spontaneous and independent. The students are provided exchange environment by the online learning committee.

\subsection{Construction of the Study Resources:}

A vital component of e-learning is the resource storehouse. Development of the study resources of e-learning consist of two partial contents. One is of curriculum resources storehouse, while the other one is of learning resources storehouse. The curriculum resources include classes for text, sound frequency, 3D simulation, and three point screens. The learning resource provides the study content to facilitate informal learning. Learning resource storehouse includes case store, trial question bank, and seminar arena. All these resources help in studying the online curriculum. These two contents support education training in a combined and inseparable manner.

\subsection{Development of Technical Support System:}

The technical support system for e-learning includes 4 aspects, which are the infrastructure, the platform, the management system and the supporting software and tools. The network infrastructure comprises of database, distributed resources, visualization technique, grid technology and a high speed network. The main components of e-learning platform are application platform and infrastructure of network. The management aspect involves managing the online curriculum, the resources and the process of learning. Some of the supporting tools and software are documents editing tool, media processing tool, the software for courseware manufacture and many more.

\section{CONCLUSIONS}

The present century is the century if digitalization and informationization. E-learning supports the widespread use of educational training. E-learning has various advantages over the traditional techniques of learning and is superior. Elearning helps in the development of agriculture education. By the help of e-learning many farmers learn the new techniques of increasing crop yields and methods of agriculture productivity in a very short time by internet.

\section{REFERENCES}

[1] http://www.dnaindia.com/academy/report-e-learningis-the-latest-fad-in-india-1550611

[2] Zhao Xiaodan, Liu Jing, E- learning and the application in Education Training, Capital Normal University,
International Conference on E-learning, E-Business, Enterprise Information Systems, and E-Government, 2009.

[3] Luo Zhongmin,Chen Chujun.E-Learning definition and characteristics: Foreign Language Education,2005.

[4] Wu Yan, Zhang Zhiqiang.E-learning and Knowledge Management: Books and intelligence,2007.

[5] S. Kakoty, and S.K Sarma. "Expert System Applications in E-learning Environment: Analysis on Current Trends and Future Prospects" International Journal of Internet Computing (IJIC), Vol. 1, 90-93, 2011.

[6] P. Gledhill, "Latest e-Learning research in Europe Middle East and Africa" (page 1 of 3), 2004.

[7] Zhao Xiaodan, Liu Jing "E-learning and the Application in Education Training “ , 2009 International Conference on E-Learning, E-Business, Enterprise Information Systems, and E-Government

[8] David R. Woolley (12 February 2013). "Wolley, David, and as so many people had insisted. Group Notes is one. "PLATO: The Emergence of Online Community."". Thinkofit.com. Retrieved 2013-10-22.

[9] Hiltz, S. (1990) 'Evaluating the Virtual Classroom', in Harasim, L. (ed.) Online Education: Perspectives on a New Environment New York: Praeger, pp. 133-169

[10] Mason. R. and Kaye, A. (1989) Mindweave: Communication, Computers and Distance Education Oxford, UK: Pergamon Press

[11] Whyte, Cassandra Bolyard (1989) Student Affairs-The Future.Journal of College Student Development.30.8689.

[12] Abdon, B \& Raab, R 2005, 'Knowledge sharing and distance learning for sustainable agriculture in the Asia-Pacific region: the role of the Internet', Plant Prod.Sci., vol. 8, no. 3, pp.298-307.

[13] Asian Forum of Parliamentarians on Population and Development 2007, 2.5 Billion increase in world population by 2050 , family planning must expand. Retrieved December 12, 2007, from http://www.afppd.org/information/info_Mar07_special. html

[14] Atchoarena, D \& Sedel, C 2003, Education and rural development: setting the framework. Retrieved December 12, 2007, from ftp://ftp.fao.org/docrep/fao/006/ad423e/ad423e01.pdf

[15] Bandalaria, M 2007, 'Impact of ICTs on open and distance learning in a developing country setting: the Philippine experience' The International Review of Research in Open and Distance Learning, vol. 8, no. 1. Retrieved December 12, 2007, from http://www.irrodl.org/index.php/irrodl/issue/view/26

[16] FAO 2005, "e-Agriculture": a definition and profile of its application. Retrieved December 12, 2007, from http://www.fao.org/rdd/doc/e-agriculture\%2014-10051.pdf 


\section{BIOGRAPHIES:}

Himanshu Agarwal: M.Tech in Software engineering from Indian Institute of Information Technology, Allahabad. His Research interest includes E-governance, E-learning and Software engineering.

Dr. Arvind Kumar: Now presently working as a scientist B in Discovery Park, Indian Institute of Information Technology, Allahabad. His research interest includes field executive, rural development, agriculture science. 